\title{
四年工作 一年完成
}

\section{中国科学院林業土壤呼究所微生物室区系組}

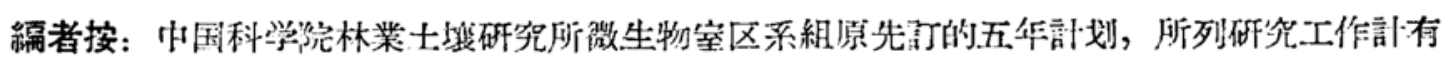
下列叫项:

1. 农業描施 (施把、妌作等) 对十㙲叶微生物区系的組成和生物学过程强度影响似研究;

2. 东北主要十类中常見細得圖陆的絀制;

3. 土坮中微生物狧恸产物的探討;

4. 微生物区系分析方法的探卻。

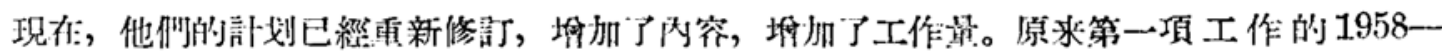
1961 胙部分, 将在 1958 年一作以內完成。除了四作工作一和完成这个人躍进以外，在新似五作

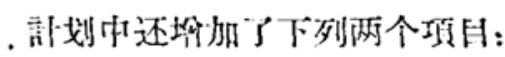

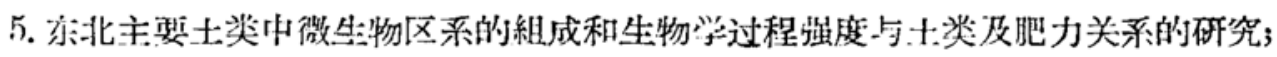

6. 东北主要士类中优势微生物群的生态和生理特性的研究。

我们这里墢表的，是他佂关于这个躍进計划的說明。

\section{一、躍进計划的特点}

1. 在原訂五年計划队 1958-1961 年研究工作的 主要部份 (累积資料) 关于施肥和季节对土境中微生 物数策和类型变化及生物学讨程强度影响的研究提前 位一年闪 (1958年) 进行。

2. 跑料試驗中优势微生场群生态与生理特征的研 究, 原訂在 1862 年幵始, 由于于整个計划提前, 在:1959 年即可着手进行。

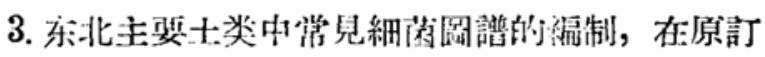

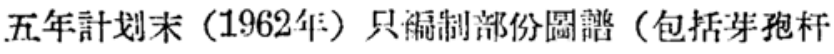

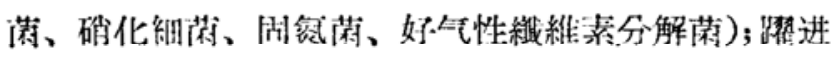

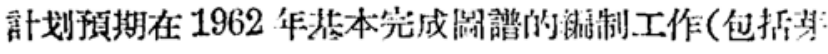

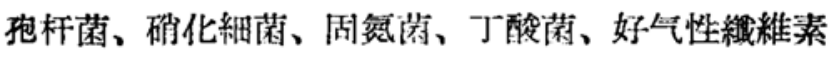
分解菌、無来狍杆蔺一部份, 夰爭取加上鉄細菌和硫 磺細菌)。这样不仪加述了圖諧的制工作, 使更多的同 志掌握分离揫定技术, 而自且地为提前在 1961 年結合 土类进行土住微生物优势群的生态地理分布和生理特 征的研究建立了基础。

4. 土脿中微生物活动产物的探討是瓷探索性的研 究。原訂五年計划中 1958-1959 年为定性分析, 1960 年开始定量分析。1962 年才旅对士塯肥力显著 的施肥处理进行物質轉化的分析, 技在不同时期測定 植物生长刺激柋、抗生物質等。由于整个計划提前三 年, 在 $\perp 959$ 年即可进行定量分析, 为深入研究創造条 件。

5. 躍进訃划在微生物区采分析方法探钨上㙞加了
內容, 抹预期在 1962 作建让起一楚比較完整的操作 規秙。

6. 在凉訂五年棓划中不进行东北主要士类中微生 物区采的組成和坐物学过程强度与土类及肥力采系的 研究，在躍进計划中提前在 1959 年即开始研究。此项

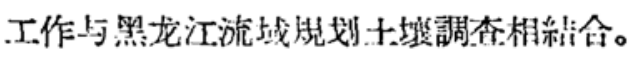

7. 在原倍五年㖕划中不进行东北主要土.类忠优势 微生物群的生态和生理特征的研究, 由于垁定工作可 以躍进, 在 1961 年将可能有条件逐步开展研究。

8. 新的五年棓划，对躴个工作间志有明确的研究 目标和深入鋝研的規划, 在苦学苦干五年后就能建立

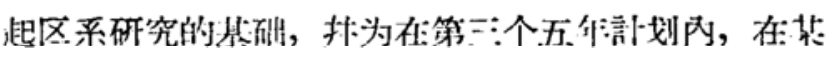

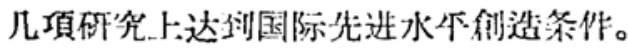

\section{二、躍进的原因}

1. 通过整風运动, 在党的教育下, 同志們的䃌会 主义敩悟提高了, 豉起了革命的于劲。

2. 党組織和朱济凡所长本人从討諭和提结躍进計 划，以及对今后如何完成計划一直給以莫大的关怀和 支持。室內其他組闹志及行政工作同志也都給以很多 的支持和鼓励。

3. 张宪武副所长（賲題目偩责人）制行五.年計划 比較具体, 使同志們能就計划进行討論和思考, 挖据 潜力。而张副所长本人和另一策任题日偩误人王祖农 先生, 在討論躍进計划中也給以大力的支持, 在業务 上进行了仔細深入的帮助。

4. 改变了原来区系組分两个小組的組織形式，把 
两个小租合扭成一个小組, 加强了業务組織領导, 对 工作量进行了科学的計算, 合理安排了組內每个同志 的工作，充分發揮了各人的积極性。原区系小組对新 罼業大学生沟有安排什么具体任务, 而躍进計划中都 分配了一定任务, 虽然按原計划有 14 人, 由于下放、 精简减少了 4 人, 但每个人要發掩出两个人的作用。

5. 把区系的調查研究与鍳定工作打成一片, 在农 業季节主要作区系研究，在冬季和初春集中力量搞分 离簽定和其他探索性試驗（如区采分析方法、土壤中 微生物活动产物等), 这样也就更充分地發揮了人力与 时閵的潜力。

6. 在保征質量和提高業务能力（包括学基础課及 查閱文献等) 方面, 桱过了具体討論分析一致認为, 由于加强了業务組織領导, 在正式試驗前多做几次准 备性試驗, 对新里業大学生給以基础訓䌀, 加之分工 明确, 計划各人心中有数, 合理支配时閏等条件, 完 全可以达到原訂五年計划中的要求。

\section{三、躍进的保証}

1. 党的領导、社会主义的优越性，这是保晸实現 躍进計划的先决条件。

2. 每个工作同志在繼續进行思想改造的基础上, 将进一步站稳工人阶級立場，一心一德，把心交給組 織、交給人民、交給柃会主义事業, 發揮集体作用, 不断鼓起革命干劲, 力爭上游, 在馬列主义思想指导 下，有組織的向科学进軍。

3. 老科学家的具体指导, 加强督促检查, 是保証 研究質量, 提高干部業务能力的关领建。

4. 行政各部門的大力支持, 各室、組間的互相合 作。

5. 学哲苏联是提高研究工作, 加速赶上国际先进 科学水平的捷径; 苏联在土堆微生物学方面, 正像其 他学科一样居于世界先列, 通过参加黑龙江流域規划

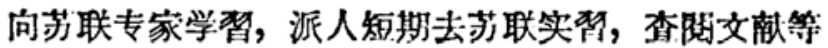
必将使工作大大推进。

6. 加强与所》有关部䅀的联系合作（如本所土裴

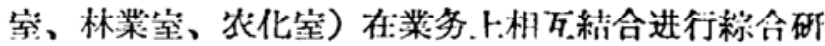
究; 争取和沈陽农学院、川东人器微生物研組在科 学研究上联系合作。

7. 躍进計划对今后几年內人力的發展作了詳細与 可靠的估計, 微生物室的研究生和留苏研究生都将陆 續参加工作和回国，每年也将不断增加新生力量。阁 志們都积極孚取有机会下放鉔炼，在有同志下放时， 全組同志将共同把任务担負起来。

\section{四、踟进計划实現的黄义}

躍进計划的实現将达到下列目标:

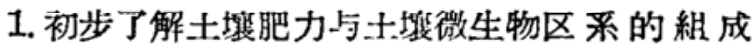

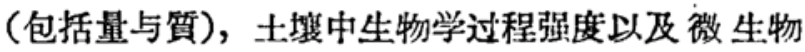
生命活动产物之間的关系。

2. 查明土壤微生物区采数量与类型的变化、生物 学过程强度等与土类的关系; 为研究土堆的生成登有 规律提供生物学資料。

3. 綃制成东北主要土类中常見細菌的圖諥，井收 集有关标准菌种, 为进一步深入研究土塯微生物区系 㓣造条件。

4. 建立起一套比較完整的土塯微生物区采的分析 方法, 緾成操作规程。

5 , 上述各項結果将为研究有机質的轉化和到殖颃 的积照創造条件。

总之, 在苦学苦干五年, 实現躍进計划后, 在十: 壤微生物区系的研究方法方面、土堆微生物分离器足定 方面及土坮中生物学过程强度的分析方法方面可以建 立起必要的基础，这就将为进一步深入研究土㙏微生 物区系，在第三个五年計划內，在某几項研究上:赶与: 国际先进水平提供出可能和有利的条件。

\section{打破陈規 建立新的工作組織形式}

琚者按: 这里發表的是中国科学院实驗生物研究所的几张大字报。在科学研究工作方 面, 以問題为中心, 通过任务安排力量, 这是正确的, 而且是最有效的一种方式，在科学为 生产服务方面說起来是如此，在学科本身的發展方面說起来，当然，亦复如是。实瞼生物研 究所的这些张大字报，不只是說明了应該这样做，这样做得通，而且也証实了必須先标思想 大躍进，然后才可能有科学的大躍进。 